\title{
Is antibiotic use associated with an increased risk of breast cancer?
}

Velicer CM, Heckbert SR, Lampe JW, Potter JD, Robertson CA, Taplin $\mathrm{SH}$. Antibiotic use in relation to the risk of breast cancer. JAMA 2004;291:827-35.

Background: To date only 1 epidemiologic study has examined the hypothesis that antibiotic use may increase the risk of breast cancer. ${ }^{1}$ That study found that premenopausal women who used antibiotics for urinary tract infections had an elevated risk of breast cancer compared with women who did not use antibiotics.

Design: The authors examined women enrolled in a large notfor-profit health plan. A total of 2266 women with primary invasive breast cancer diagnosed between Jan. 1, 1993 and June 30, 2001 were matched with 7953 randomly selected female control subjects based on age and length of enrollment in the health plan. Computerized pharmacy records were used to determine antibiotic use. The authors examined the sensitivity of the results to a variety of assumptions $\approx$ about antibiotic exposure.

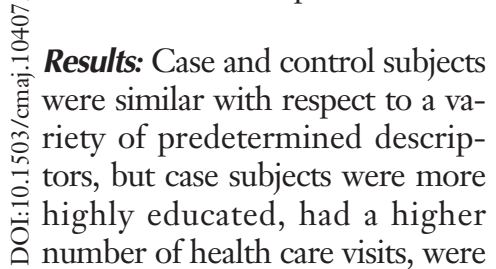

Table 1: Association of incident breast cancer with cumulative days of antibiotic use*

\begin{tabular}{|c|c|c|c|}
\hline \multirow[b]{2}{*}{$\begin{array}{l}\text { Cumulative } \\
\text { no. of days of } \\
\text { antibiotic use }\end{array}$} & \multicolumn{2}{|c|}{ No. (and \%) } & \multirow[b]{2}{*}{ OR $(95 \% \mathrm{Cl}) \dagger \neq$} \\
\hline & $\begin{array}{l}\text { Control } \\
\text { subjects } \\
n=7948\end{array}$ & $\begin{array}{c}\text { Case } \\
\text { subjects } \\
n=2266\end{array}$ & \\
\hline 0 & $1478(18.6)$ & $332(14.7)$ & Reference \\
\hline $1-50$ & 2365 (29.8) & $675(29.8)$ & $1.45(1.24-1.69)$ \\
\hline $51-100$ & 1515 (19.1) & $435(19.2)$ & $1.53(1.28-1.83)$ \\
\hline $101-500$ & $2215(27.9)$ & $682(30.1)$ & $1.68(1.42-2.00)$ \\
\hline 501-1000 & $214(2.7)$ & $83(3.7)$ & $2.14(1.60-2.88)$ \\
\hline$>1000$ & $161(2.0)$ & $59(2.6)$ & $2.07(1.48-2.89)$ \\
\hline
\end{tabular}

Notes: $\mathrm{OR}=$ odds ratio, $\mathrm{Cl}=$ confidence interval.

*Adapted from Velicer CM, Heckbert SR, Lampe JW, Potter JD, Robertson CA Taplin SH. Antibiotic use in relation to the risk of breast cancer. JAMA 2004;291:827-35.

tORs adjusted for age and length of enrollment in the health plan. $\neq p<0.001$. more likely to have undergone hormone replacement therapy and were more likely to exhibit factors known to be associated with breast cancer. An association was observed between increase in cumulative days of antibiotic use and increased risk of incident fect persisted after adjustment for a variety of factors known to be associated with breast cancer. The association was seen in preand postmenopausal women and in users of antibiotics for any indication. The results were robust in that similar effects were seen regardless of the assumptions related to antibiotic exposure that were incorporated into the analyses. The association between antibiotic use and death caused by breast cancer was similar to that observed for incident breast cancer, suggesting that health careseeking behaviours did not increase the rate of earlier breast cancer detection.

Commentary: The authors describe an association between antibiotic use and increased breast cancer risk that persisted after adjustment for factors known to be associated with breast cancer. The question remains as to whether antibiotic use is causally related to breast cancer or whether there are common mediators of antibiotic use and breast cancer. For example, some women may have underlying immune or inflammatory disorders that might predispose them to neoplasia or infections. In that case, antibiotic use would only be a marker for such a predisposition. If this hypothesis were true, one would also expect an increased frequency of other types of malignancies to be associated with antibiotic use. In this study only breast cancer (Table 1). This ef- breast cancers were examined.

Although there are a number of interesting proposed mechanisms related to interference with intestinal microflora and estrogen production that suggest a potential causal relation between antibiotic use and breast cancer, ${ }^{2}$ these hypotheses remain unproven after this case-control study.

Practice implications: The authors conclude that additional studies are required before the implications for clinical practice are clear. However, they do suggest prudence in antibiotic use until such studies are conducted. Is this suggestion warranted by the available data? The results of the study should not dissuade physicians from prescribing antibiotics or women from taking them when there are legitimate indications to do so. This study simply generates a number of interesting hypotheses. There are already good arguments for exercising prudence when antibiotics are not clearly indicated or when other therapeutic options exist. ${ }^{3,4}$ The current study, its limitations notwithstanding, adds yet another argument to that list.

\section{Carol Sawka}

Vice President

Regional Cancer Services

Sunnybrook and Women's College

Health Sciences Centre

Toronto, Ont.

\section{References}

1. Knekt P, Aldercreutz H, Rissaner H, Aromaa A, Teppo L, Heliovaara M. Does antibacterial treatment for urinary tract infection contribute to the risk of breast cancer? Br 7 Cancer 2000;82: $1107-10$

2. Gorbach SL. Estrogens, breast cancer and intestinal flora. Rev Infect Dis 1984;6[Suppl]:S85-90.

3. Louie JP, Bell LM. Appropriate use of antibiotics for common infections in an era of increasing resistance. Emerg Med Clin North Am 2002;20:69-91.

4. Belongia EA, Schwartz B. Strategies for promoting judicious use of antibiotics by doctors and patients. $B M \mathcal{F}$ 1998;317:668-71. 